\title{
PENGARUH KEPEMIMPINAN TRANSFORMASIONAL TERHADAP KREATIVITAS KARYAWAN DIMEDIASI EFIKASI DIRI KREATIF PADA PT. AURA BALI CRAFT
}

\author{
Ida Ayu Dewi Wijayanti ${ }^{1}$ \\ I Wayan Gede Supartha² \\ ${ }^{1,2}$ Fakultas Ekonomi dan Bisnis Universitas Udayana, Bali, Indonesia \\ email : dayudewiwijayanti@gmail.com
}

\begin{abstract}
ABSTRAK
Pengaruh kepemimpanan transformasional terhadap kreativitas karyawan yang dimediasi efikasi diri kreatif pada PT. Aura Bali Craft merupakan tujuan daripada penelitian ini. Penelitian ini menggunakan sampel sebanyak 33 karyawan operasional yang ditentukan menngunakan sampel jenuh. Kuesioner dijadikan sebagai teknik pengumpulan data dengan menggunakan metode pengukuran skala Likert serta data dianalisis dengan mempergunakan uji asumsi klasik serta teknik analisis jalur. Perolehan akhir dari penelitian menunjukkan variabel kepemimpinan transformasional dan efikasi diri kreatif secara positif berpengaruh signifikan kreativitas karyawan. PT. Aura Bali Craft sebaiknya menerapkan kepemimpinan transformasional dengan baik sehingga dapat meningkatkan keyakinan kreatif karyawan yang akan berdampak pada kreativitas karyawan.
\end{abstract}

Kata kunci: kreativitas karyawan, efikasi diri kreatif, kepemimpinan transformasional

\begin{abstract}
The aims of this watchfulness to explain the clout of transformational leadership on employee creativity mediated by creative self-efficacy at PT. Aura Bali Craft. The sample used was 33 operational employee who were determined by the saturated sample method. Data collection techniques used were questionnaires using Likert scale measurement methods and data were analyzed by path analysis techniques. The yield indicate the variables of transformational leadership and creatives self-efficacy take a positive and significant clout on employee creativity. PT. Aura Bali Craft should apply transformational leadership well so that it can increase employees creative beliefs that will have an impact on employee creativity.
\end{abstract}

Keywords: transformasional leadership, creative self-efficacy, employee creativity 


\section{PENDAHULUAN}

Industri kerajinan tangan merupakan salah satu jenis industri dalam sektor industri kreatif. Saat ini, pemerintah sangat memperhatikan perkembangan dari industri kreatif. Pemerintah pusat dan daerah diharapkan memfasilitasi serta mengembangkan kreativitas dan inovasi masyarakat. Perkembangan industri kerajinan tangan di Bali kini semakin semarak. Kehadiran para pelaku usaha telah memberi warna tersendiri bagi perkembangan industri kerajinan tangan.

Industri kerajinan tangan di Bali dituntut agar dapat mempersiapkan beragam cara agar berkembang serta mamajukan daya saingnya. Pencapaian tujuan dari industri kerajinan tangan agar dapat bersaing tentu akan didukung adanya sumber daya manusia yang handal, sehingga unggul dalam bersaing (Bakhtiar dkk., 2009). Sumber daya manusia merupakan suatu aspek pada bidang produksi yang tidak mungkin dilalaikan dari pelaku usaha, sebab sumber daya manusia yang merencanakan dan penggerak dari seluruh kegiatan badan usaha (Rizi et al., 2013).

Komponen-komponen yang mempengaruhi kreativitas karyawan terdiri atas faktor internal serta faktor eksternal (Mustika, 2017). Faktor internal tersebut tertanam didalam diri karyawan itu sendiri yaitu gaya kognitif serta kepribadian. Sementara, faktor eksternal berasal dari pengaruh luar yaitu dukungan pemimpin, dukungan rekan kerja dan karaktersitik pekerjaan.

Berdasarkan hasil pra survei yang dilakukan kepada 15 orang karyawan PT. Aura Bali Craft dapat dijelaskan bahwa dari 15 responden terdapat 9 responden yang mampu menunjukkan keaslian ketika bekerja, sedangkan 6 responden belum 
Ida Ayu Dewi Wijayanti, Pengaruh Kepemimpinan Transformasional...

dapat menunjukkan orisinalitasnya pada saat bekerja. Kemudian, 3 responden dapat menemukan fungsi baru dari peralatan yang sudah ada, dan 12 responden mengaku sulit untuk menemukan kegunaan baru dari peralatan yang ada. Lalu, 8 responden yakin mampu untuk memecahkan masalah yang ada dalam pekerjaan, sedangkan 7 responden mengatakan tidak mampu memecahkan masalah yang timbul dalam pekerjaan. Serta, terdapat 6 responden menyatakan mampu menghasilkan ide unik yang dapat diterapkan sehubungan dengan pekerjaan, dan 9 responden mengaku belum mampu untuk menghasilkan ide unik tersebut. Jadi, berdasarkan hasil pra survei yang dilaksanakan peneliti, menyimpulkan bahwa kreativitas karyawan PT. Aura Bali Craft tampak masih belum maksimal. Dengan melihat hasil pra survei yang berbeda dengan penelitian sebelumnya, maka penulis bertujuan untuk melaksanakan penelitian kembali dan membahas hal tentang pengaruh kepemimpinan transformasional terhadap kreativitas karyawan yang dimediasi oleh efikasi diri kreatif.

Berlandaskan pemaparan latar belakang diatas, sehingga rumusan masalah penelitian 1) Bagaimana pengaruh kepemimpinan tranformasional terhadap efikasi diri kreatif? ; 2) Bagaimana pengaruh efikasi diri kreatif terhadap kreativitas karyawan? ; 3) Bagaimana pengaruh kepemimpinan transformasional terhadap kreativitas karyawan? ; 4) Bagaimana peran efikasi diri kreatif memediasi kepemimpinan transformasional terhadap kreativitas karyawan?

Sasaran daripada penelitian 1) Untuk menjelaskan pengaruh kepemimpinan transformasional terhadap efikasi diri kreatif ; 2) Untuk menjelaskan pengaruh efikasi diri kreatif terhadap kreativitas karyawan ; 3) 
Untuk menjelaskan pengaruh kepemimpinan transformasional terhadap kreativitas karyawan ; 4) Untuk menjelaskan peran efikasi diri kreatif memediasi kepemimpinan transformasional terhadap kreativitas karyawan.

Manfaat dalam penelitian ini, pertama manfaat teoritis yang mana penelitian ini harapannya dapat memberikan suatu informasi dan pengetahuan perihal kepemimpinan transformasional, efikasi diri kreatif, dan kreativitas karyawan. Kedua, manfaat praktis dari penelitian ini kedepannya mampu memberi informasi dan memberi masukan kepada manajemen PT. Aura Bali Craft untuk meningkatkan kreativitas karyawan melalui kepemimpinan transformasional dan efikasi diri kreatif.

Dasar penelitian dalam penelitian ini merupakan teori komponensial yang berarti menjelaskan bahwa dukungan positif dari pemimpin akan membantu dalam menetapkan tujuan yang tepat, mendukung kelompok kerja dalam organisasi, mengakui kontribusi karyawan, memberikan umpan balik yang membangun, menunjukan kepercayaan dalam kelompok kerja, dan menumbuhkan lingkungan yang terbuka untuk ide kerja baru (Cheung dan Wong, 2011).

Kemampuan seseorang untuk mengemukakan inovasi baru berupa gagasan yang mempunyai unsur lama dan dapat diperbaharui ke dalam konfigurasi melalui dimensi konten verbal merupakan kreativitas karyawan (Sanny dkk., 2013). Kreativitas adalah gagasan baru yang berguna mengenai prosedur proses, produk, dan jasa oleh seorang karyawan (Shin et al., 2012). Karyawan yang mempunyai gagasan kreatif dan dikembangkan untuk mengimplementasikan gagasan tersebut, menerapkan dan menginformasikan gagasan tersebut untuk rekan kerja di 
Ida Ayu Dewi Wijayanti, Pengaruh Kepemimpinan Transformasional...

perusahaan (Marasabessy dan Santoso, 2014). Kreativitas dalam pengembangan gagasan merupakan suatu tindakan kreatif yang tidak terbatas, termasuk dalam pengembangan keputusan ataupun pemecahan suatu masalah (Sanny dkk., 2013).

Pemimpin yang mampu untuk memberikan inspirasi serta motivasi kepada karyawan agar mampu mendapatkan tujuan yang lebih tepat dari yang direncanakan disebut sebagai kepemimpinan transformasional (Gibson et al., 1997: 86). Kepemimpinan transformasional mempunyai tiga karakteristik utama yaitu, karisma, pertahanan individu pada karyawan dan stimulasi intelektual pada karyawan (Gibson et al., 1997: 90). Para pemimpin transformasional juga dikatakan sebagai pemimpin yang mampu memberikan inspirasi para karyawannya untuk meenghindari kepentingan sendiri dan memiliki kemampuan mempengaruhi para karyawannya (Robbins dan Judge, 2015: 261). Perilaku kepemimpinan transformasional memberikan arahan kepada perasaan pengendalian diri yang positif antara para karyawannya, dimana diharapkan dapat meningkatkan kreativitas karyawan ketika bekerja. Kepemimpinan akan mempengaruhi bawahannya yang nantinya terlihat pada visi suatu perusahaan (Kusuma dan Rahardja, 2018). Oleh karena itu kepemimpinan transformasional mampu memberi dampak positif yang kedepannya karyawan merasakan kekaguman, kesetiaan, penghormatan terhadap pemimpin, kepercayaan serta karyawan mendapatkan suatu tmotivasi dalam melaksanakan suatu pekerjaan daripada yang diharapkan pada awalnya.

Efikasi diri merupakan keyakinan individu dalam kemampuannya untuk melakukan tugas yang diberikan (Bandura, 2007). Efikasi diri dalam aktivitas 
kreatif adalah kunci untuk lebih kreatif, karyawan dapat memajukan keterlibatan dalam perilaku kreatif ketika merasakan tingkat kepercayaan diri yang tinggi dalam keefektifan diri mereka untuk kreativitas (Wang et al., 2014). Efikasi diri kreatif merupakan pengembangan dari efikasi diri yang mengacu pada keyakinan bahwa individu memiliki kemampuan untuk menghasilkan sesuatu hal yang kreatif (Malik et al., 2014). Pengembangan efikasi diri kreatif memberikan pandangan dinamis tentang bagaimana individu merumuskan dan mengubah penilaian efektivitas dari waktu ke waktu dan pengalaman dalam pengaturan kerja (Tierney dan Farmer, 2011). Efikasi diri kreatif juga merupakan penilaian kapasitas yang dibuat untuk memicu kreativitas pada karyawan (Karwowski, 2011). Diperlukan melakukan suatu usaha untuk melaksanakan suatu upaya yang kratif. Oleh karena itu, tindakan kreatif bisa dilaksanakan secara konsisten guna menghadapai berbagai rintangan sehingga ketekunan itu sangat penting untuk dipertahankan. Upaya kreatif merupakan prasyarat penting untuk mencapai efikasi diri kreatif (Mathisen dan Bronnick, 2009).

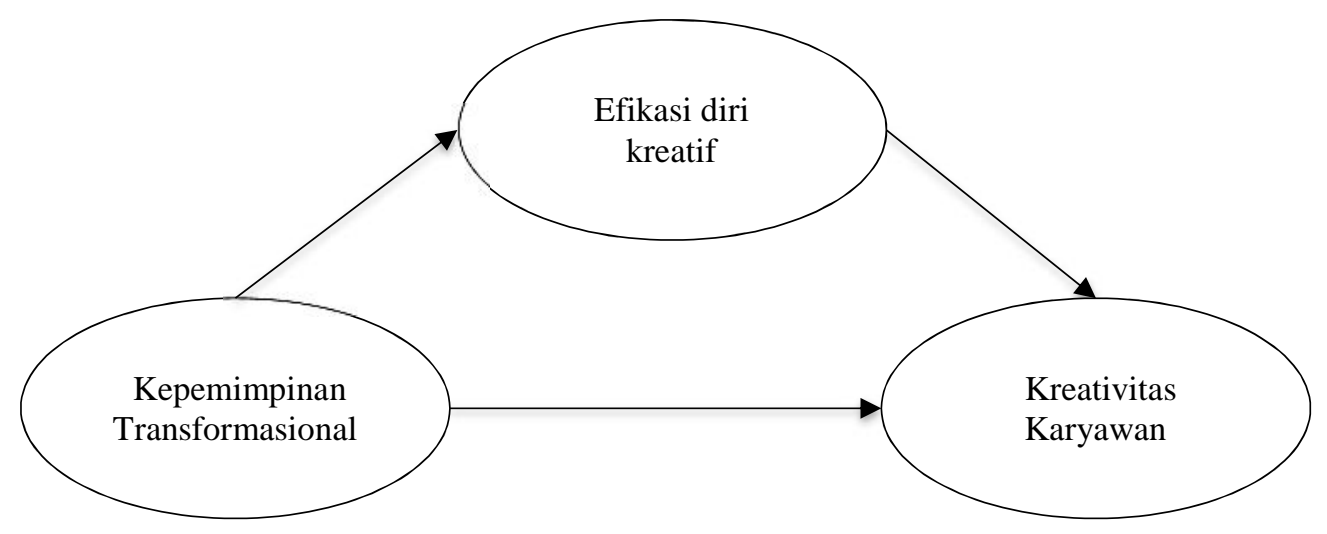

Gambar 1. Kerangka Konseptual

Sumber: Chen dan Zhang (2017), Cheung dan Wong (2011), Gong et al. (2009), Gumusluoglu dan Ilsev (2009), Henker et al. (2014), Mittal dan Dhar (2015), Wang et al. (2014), Waterwall et al. (2017), Affar dan Massod (2017), Newman et al. (2018), Hirst et al. (2015), dan Song et al. (2018) 
Ida Ayu Dewi Wijayanti, Pengaruh Kepemimpinan Transformasional...

Menurut Mittal dan Dhar (2015) kepemimpinan transformasional berpengaruh terhadap kreativitas karyawan, ini berarti karakteristik perilaku seorang pemimpin dapat menghasilkan kreativitas karyawan. Penelitian tersebut diperkuat dengan pendapat dari Cheung dan Wong (2011) yang menyatakan bahwa kepemimpinan transformasional berhubungan positif dengan kreativitas karyawan. Hal tersebut didukung dengan penelitian Gumusluoglu dan Ilsev (2009), Henker et al. (2014), Gong et al. (2009), serta Wang et al. (2014) menyebutkan bahwa kreativitas karyawan dipengaruhi secara positif dengan kepemimpinan transformasional. Bahkan kepemimpinan transformasional secara positif mempromosikan efikasi diri karyawan, sebagai pemimpin transfosmasional memberikan persuasi verbal dan gairah psikologis untuk mengembangkan efikasi diri karyawan (Bass dan Avolio, 1992). Berlandaskan pemaparan sebelumnya, oleh karena itu dibuat hipotesis penelitian yaitu.

$\mathrm{H}_{1}$ : Kepemimpinan transformasional berpengaruh positif terhadap kreativitas karyawan

Persoalan ini diperkuat dengan pendapat dari Mittal dan Dhar (2015) yang mengemukakan bahwa kepemimpinan transformasional berpengaruh terhadap efikasi diri kreatif. Wang et al. (2014) mengemukakan bahwa kepemimpinan transformasional memiliki hubungan yang positif dengan efikasi diri kreatif. Penelitian lain yang dilaksanakan oleh Waterwall et al. (2014), Afsar dan Masood (2017) serta Newman et al. (2018) juga menyatakan hal yang sama yaitu kepemimpinan transformasional berhubungan positif dengan efikasi diri kreatif. Hal ini berarti bila kepemimpinan transformasional ditingkatkan, maka efikasi diri 
kreatif dalam individu akan menjadi semakin tinggi. Berlandaskan pemaparan sebelumnya, oleh karena itu dibuat hipotesis penelitian yaitu.

$\mathrm{H}_{2}$ : Kepemimpinan transformasional berpengaruh positif terhadap efikasi diri kreatif

Individu dengan efikasi diri kreatif yang tinggi akan menekankan proses yang berhubungan dengan kreatif dalam produksi ide atau solusi, dan individu dengan efikasi diri kreatif yang tinggi akan berusaha lebih keras untuk memecahkan suatu masalah dan menghasilkan ide. Efikasi diri kreatif memiliki hubungan positif dengan kreativitas karyawan (Chen dan Zhang, 2017). Penelitian yang dilaksanakan Waterwall et al. (2017) dan Hirst et al. (2015) juga menyebutkan bahwa efikasi diri kreatif berhubungan positif dengan kreativitas. Hal ini berarti bila efikasi diri kreatif dalam diri seseorang tinggi, maka kreativitas yang dihasilkan akan menjadi semakin baik. Berlandaskan pemaparan sebelumnya, oleh karena itu dibuat hipotesis penelitian yaitu.

$\mathrm{H}_{3}$ : Efikasi diri kreatif berpengaruh positif terhadap kreativitas karyawan

Mittal dan Dhar (2015) menyatakan bahwa pemimpin transformasional mengambil langkah proaktif untuk menghasilkan pemikiran kreatif dan mengharapkan hal yang sana dari para karyawan. Mittal dan Dhar (2015) juga menyatakan bahwa efikasi diri kreatif berperan sebagai mediasi hubungan antara kepemimpinan transformasional serta kreativitas karyawan.

Gong et al. (2009) berpendapat bahwa kepemimpinan transformasional meningkatkan pemikiran karyawan yang independen dan kritis. Pernyataan Gong et al. (2009) ini didukung berdasarkan hasil penelitiannya yang menyatakan 
Ida Ayu Dewi Wijayanti, Pengaruh Kepemimpinan Transformasional...

bahwa efikasi diri kreatif memediasi hubungan antara kepemimpinan transformasional dengan kreativitas karyawan. Penelitian lain yang dilaksanakan Wang et al. (2014) dan Song et al. (2018) menyatakan bahwa efikasi diri kreatif memediasi pengaruh kepemimpinan transformasional terhadap kreativitas karyawan. Berdasarkan penjelasan diatas, maka dibuat hipotesis penelitian sebagai berikut.

$\mathrm{H}_{4}$ : Efikasi diri kreatif memediasi pengaruh kepemimpinan transformasional terhadap kreativitas karyawan

\section{METODE PENELITIAN}

Metode penelitian ini adalah asosiatif kausalitas dimana untuk mengetahui pengaruh antar variabel dan mempunyai sifat sebab akibat. Penelitian dilakukan pada PT. Aura Bali Craft. Obyek penelitian adalah kepemimpinan transformasional $(\mathrm{X})$, efikasi diri kreatif $(\mathrm{M})$ dan kreativitas karyawan (Y). Populasi ialah seluruh karyawan pada bagian operasional PT. Aura Bali Craft sebanyak 33 orang karyawan. Sampel adalah pihak daripada kuantitas serta karakteristik yang dipunyai oleh populasi. Metode yang digunakan damal penentuan kuantitas dalam sapel adalah dengan menggunkan metode sampel jenuh.

Metode pengumpulan data menggunakan metode kuesioner melalui pendekatan survei. Kuesioner akan disebarkan kepada karyawan PT. Aura Bali Craft dan pengisian kuesioner yang telah dosebarkan akan didampingi oleh peneliti. Pengukuran jawaban yang dimana nantinya di dapat dari kuesioner responden akan diukur dengan skala Likert. Jawaban dari setiap penyataan yang 
dijawab oleh responden akan mempunyai skor atau nilai tersendiri yang dimulai dengan sangat setuju hingga sangat tidak setuju. Setiap pernyataan akan diberikan angka agar dapat mempermudah perhitungan dalam penelitian. Uji asumsi klasik dan analisis jalur yang menjadi teknik analisis data pada penelitian ini.

\section{HASIL DAN PEMBAHASAN}

Tabel 1.

Karakteristik Responden

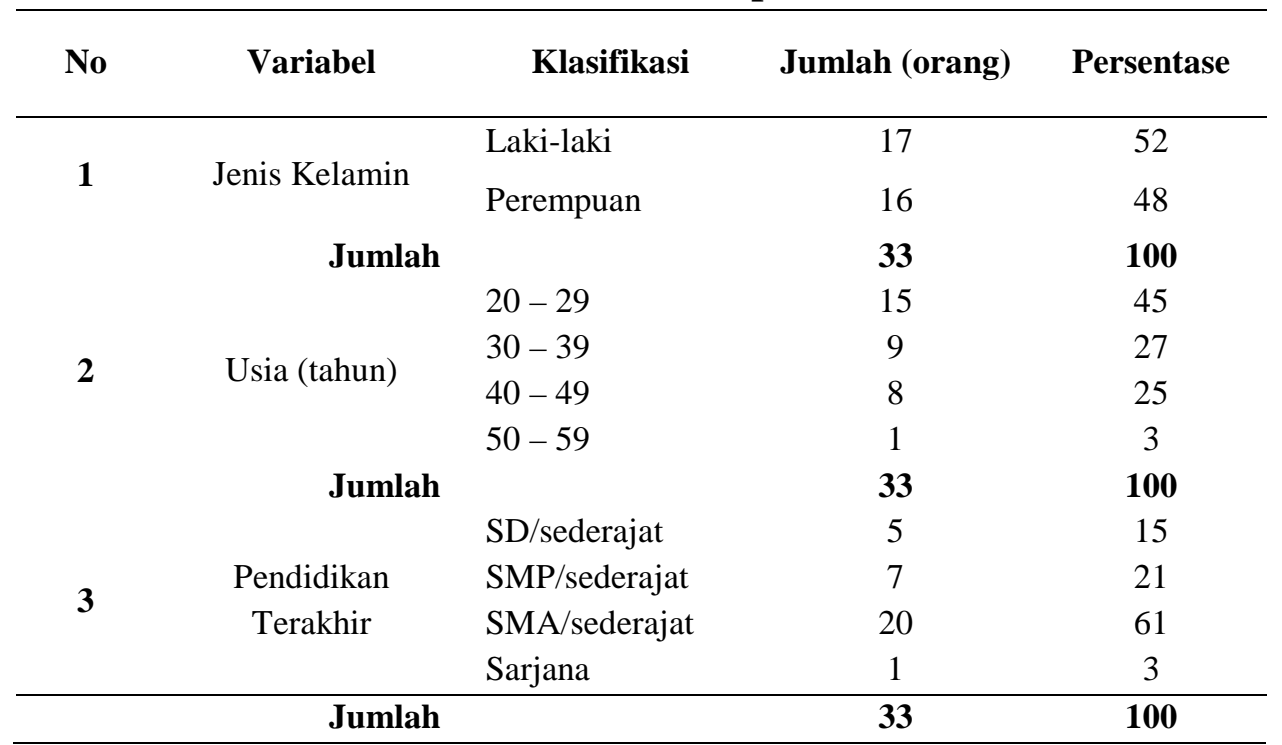

Sumber : Data Primer Diolah, 2018

Karakteristik responden pada penelitian ini terdiri atas profil dari 33 responden yang ikut berkontribusi untuk mengisi kuesioner. Profil responden tersebut menjelaskan pendidikan terakhir, jenis kelamin, dan usia. Secara rinci akan disajikan pada Tabel 1 yang menjelaskan bahwa responden perempuan lebih sedikit dibandingkan dengan responden laki-laki dimana responden laki-laki sebanyak 52 persen sementara responden perempuan sebanyak 48 persen. Klasifikasi usia, sebagian besar responden berusia $20-29$ tahun sebesar 45 persen, lalu usia 30 - 39 tahun sebesar 27 persen, usia 40 - 49 tahun sebesar 25 
Ida Ayu Dewi Wijayanti, Pengaruh Kepemimpinan Transformasional...

persen, dan usia 50 - 59 tahun sebesar 3 persen. Hal ini berarti menjelaskan bahwa usia 20 -29 tahun yang mana merupakan usia produktif, dimana cenderung lebih memiliki ide kreatif dibandingkan dengan rentang usia diatas 29 tahun. Dilihat berdasarkan tingkat pendidikan terakhir responden sebagian besar memiliki tingkat pendidikan SMA/sederajat sebesar 61 persen, kemudian SMP/sederajat sebesar 21 persen, SD/sederajat sebesar 15 persen, dan Sarjana sebesar 3 persen.

Uji validitas memiliki kriteria angka korelasi antara skor item pada total item kemudian dibandingkan oleh $r$ kritis. Apabila angkar korelasi item yang di dapat lebih besar daripada $\mathrm{r}$ kritis (0.30) alhasil instrumen dapat dinyatakan valid (Sugiyono, 2014: 177).

Tabel 2.

Hasil Uji Validitas Instrumen pada Variabel Kepemimpinan Transformasional

\begin{tabular}{|c|c|c|c|}
\hline No & Indikator & rhitung & Keterangan \\
\hline 1 & X1. 1 & 0.631 & Valid \\
\hline 2 & X1. 2 & 0.425 & Valid \\
\hline 3 & $\mathrm{X} 1.3$ & 0.721 & Valid \\
\hline 4 & X1. 4 & 0.696 & Valid \\
\hline 5 & $\mathrm{X} 1.5$ & 0.679 & Valid \\
\hline 6 & X1. 6 & 0.643 & Valid \\
\hline 7 & X1. 7 & 0.692 & Valid \\
\hline 8 & X1. 8 & 0.587 & Valid \\
\hline 9 & X1. 9 & 0.732 & Valid \\
\hline 10 & $\mathrm{X} 1.10$ & 0.586 & Valid \\
\hline 11 & $\mathrm{X} 1.11$ & 0.645 & Valid \\
\hline 12 & $\mathrm{X} 1.12$ & 0.615 & Valid \\
\hline 13 & X1. 13 & 0.620 & Valid \\
\hline 14 & X1. 14 & 0.687 & Valid \\
\hline 15 & $\mathrm{X} 1.15$ & 0.605 & Valid \\
\hline
\end{tabular}

Sumber: Data Primer Diolah, 2018 
Tabel 3.

Hasil Uji Validitas Instrumen pada Efikasi Diri Kreatif

\begin{tabular}{ccccc}
\hline No & & Indikator & rhitung & Keterangan \\
\hline 1 & M1. 1 & 0.611 & Valid \\
2 & M1.2 & 0.775 & Valid \\
3 & M1.3 & 0.725 & Valid \\
4 & M1. & & 0.588 & Valid \\
5 & M1.5 & 0.745 & Valid \\
6 & M1.6 & 0.809 & Valid \\
\hline
\end{tabular}

Sumber: Data Primer Diolah, 2018

Tabel 4.

Hasil Uji Validitas Instrumen pada Variabel Kreavitas Karyawan

\begin{tabular}{ccccc}
\hline No & & Indikator & rhitung & Keterangan \\
\hline 1 & Y1. 1 & 0.714 & Valid \\
2 & Y1. 2 & 0.714 & Valid \\
3 & Y1.3 & 0.723 & Valid \\
4 & Y1.4 & 0.775 & Valid \\
5 & Y1.5 & 0.515 & Valid \\
6 & Y1.6 & 0.600 & Valid \\
7 & Y1.7 & 0.882 & Valid \\
\hline
\end{tabular}

Sumber: Data Primer Diolah, 2018

Uji reliabilitas berguna mengetahui seberapa konsisten alat ukur yang diterapkan. Pengukiran reliabilitas instrument dengan menggunakan metode Cronbach's Alpha, nilai suatu instrumen akan dikatakan reliabel jikalau ukuran variabel lebih besar 0.60 (Sugiyono, 2014: 183). Pengujian reliabilitas dalam kajian ini dipaparkan dalam Tabel 5.

Tabel 5.

Hasil Uji Reliabilitas Instrumen Penelitian

\begin{tabular}{lcc}
\hline \multicolumn{1}{c}{ Variabel } & Alpha Cronbachs & Keterangan \\
\hline Kepemimpinan Transformasional & 0.894 & Reliabel \\
Kreativitas Karyawan & 0.833 & Reliabel \\
Efikasi Diri Kreatif & 0.796 & Reliabel \\
\hline
\end{tabular}

Sumber: Data Primer Diolah, 2018

Deskripsi pandangan responden mengenai variabel-variabel pada penelitian memerlukan penentuan distribusi frekuensi dilihat dengan berdasarkan 
Ida Ayu Dewi Wijayanti, Pengaruh Kepemimpinan Transformasional...

nilai intervalnya (Wirawan, 2014: 33). Menentukan nilai interval penilai responden yakni.

Tabel 6.

Deskripsi Jawaban Responden Mengenai Penilaian terhadap Variabel Kepemimpinan Transformasional

\begin{tabular}{|c|c|c|c|c|c|c|c|c|c|}
\hline \multirow{2}{*}{ No. } & \multirow{2}{*}{$\begin{array}{c}\text { Pernyataan Kepemimpinan } \\
\text { Transformasional (X1) }\end{array}$} & \multicolumn{5}{|c|}{ Jawaban Responden } & \multirow{2}{*}{$\begin{array}{l}\text { Jml. } \\
\text { Res. }\end{array}$} & \multirow{2}{*}{$\begin{array}{l}\text { Rata- } \\
\text { Rata }\end{array}$} & \multirow[t]{2}{*}{ Ket. } \\
\hline & & 1 & 2 & 3 & 4 & 5 & & & \\
\hline 1 & Memunculkan rasa bangga & 0 & 2 & 5 & 12 & 14 & 33 & 4.15 & Baik \\
\hline 2 & $\begin{array}{l}\text { Mengutamakan kepentingan } \\
\text { perusahaan }\end{array}$ & 0 & 0 & 15 & 12 & 6 & 33 & 3.73 & Baik \\
\hline 3 & Percaya diri & 0 & 0 & 10 & 13 & 10 & 33 & 4.00 & Baik \\
\hline 4 & Berprinsip & 1 & 0 & 5 & 16 & 11 & 33 & 4.09 & Baik \\
\hline 5 & Mempunyai tujuan & 0 & 0 & 9 & 13 & 11 & 33 & 4.06 & Baik \\
\hline 6 & Kebersamaan & 0 & 0 & 4 & 12 & 17 & 33 & 4.39 & $\begin{array}{l}\text { Sangat } \\
\text { Baik }\end{array}$ \\
\hline 7 & Memberi pelatihan & 0 & 2 & 6 & 13 & 12 & 33 & 4.06 & Baik \\
\hline 8 & $\begin{array}{l}\text { Mengetahui kemampuan } \\
\text { karyawan }\end{array}$ & 0 & 0 & 4 & 12 & 17 & 33 & 4.39 & $\begin{array}{l}\text { Sangat } \\
\text { Baik }\end{array}$ \\
\hline 9 & $\begin{array}{l}\text { Mengembangkan kemampuan } \\
\text { karyawan }\end{array}$ & 0 & 1 & 8 & 12 & 12 & 33 & 4.06 & Baik \\
\hline 10 & Antusias & 1 & 1 & 3 & 15 & 13 & 33 & 4.15 & Baik \\
\hline 11 & Memiliki keyakinan tinggi & 0 & 2 & 3 & 17 & 11 & 33 & 4.12 & Baik \\
\hline 12 & Optimis & 0 & 1 & 6 & 20 & 6 & 33 & 3.94 & Baik \\
\hline 13 & Teliti & 1 & 0 & 8 & 16 & 8 & 33 & 3.91 & Baik \\
\hline 14 & Berpikiran terbuka & 1 & 3 & 7 & 12 & 10 & 33 & 3.82 & Baik \\
\hline 15 & Inovatif & 0 & 1 & 6 & 14 & 12 & 33 & 4.12 & Baik \\
\hline & Rata & & & & & & & 4.06 & Baik \\
\hline
\end{tabular}

Sumber: Data Primer Diolah, 2018

Hasil akhir dari tabulasi data mengenai jawaban responden dalam menanggapi 15 pernyataan mengenai kepemimpinan transformasional pada karyawan PT. Aura Bali Craft dimana terdapat 33 responden yang menjawab. Kelengkapan data dijelaskan dalam Tabel 6. 
Tabel 6 memaparkan dimana 15 pernyataan variabel kepemimpinan transformasional mendapatkan penilaian rata - rata sebesar 4.06 dan termasuk ke dalam kategori penilaian $3.40-4.19$ yaitu baik. Ini berarti menyatakan bahwa karyawan PT. Aura Bali Craft yang menjadi responden dalam penelitian ini setuju bahwa kepemimpinan transformasional merupakan nilai yang karyawan tersebut rasakan ketika bekerja.

\section{Tabel 7.}

\section{Deskripsi Jawaban Responden Mengenai Penilaian terhadap Variabel} Efikasi Diri Kreatif

\begin{tabular}{|c|c|c|c|c|c|c|c|c|c|}
\hline \multirow{2}{*}{ No. } & \multirow{2}{*}{$\begin{array}{c}\text { Pernyataan Efikasi Diri Kreatif } \\
\text { (M1) }\end{array}$} & \multicolumn{5}{|c|}{ Jawaban Responden } & \multirow[t]{2}{*}{$\begin{array}{l}\text { Jml. } \\
\text { Res. }\end{array}$} & \multirow[t]{2}{*}{$\begin{array}{l}\text { Rata- } \\
\text { Rata }\end{array}$} & \multirow[t]{2}{*}{ Ket. } \\
\hline & & 1 & 2 & 3 & 4 & 5 & & & \\
\hline 1 & Mampu menyelesaikan masalah & 0 & 3 & 12 & 14 & 4 & 33 & 3.58 & Tinggi \\
\hline 2 & Kemampuan kreatif & 0 & 1 & 10 & 13 & 9 & 33 & 3.91 & Tinggi \\
\hline 3 & Memiliki kecerdikan & 0 & 1 & 7 & 18 & 7 & 33 & 3.94 & Tinggi \\
\hline 4 & $\begin{array}{l}\text { Keyakinan mengatasi situasi yang } \\
\text { sulit }\end{array}$ & 1 & 1 & 10 & 10 & 11 & 33 & 3.88 & Tinggi \\
\hline 5 & Pemikiran kreatif & 0 & 2 & 6 & 15 & 10 & 33 & 4.00 & Tinggi \\
\hline 6 & Memberi solusi yang orisinal & 1 & 2 & 8 & 16 & 6 & 33 & 3.73 & Tinggi \\
\hline \multicolumn{8}{|c|}{ Rata - rata } & 3.84 & Tinggi \\
\hline
\end{tabular}

Sumber: Data Primer Diolah, 2018

Tabel 7 memaparkan bahwa penilaian responden terhadap 6 pernyataan mengenai efikasi diri kreatif pada karyawan PT. Aura Bali Craft yang dijawab oleh 33 responden. Berdasarkan data Tabel 7 menunjukkan bahwa 6 pernyataan mengenai efikasi diri kreatif mendapatkan penilaian rata - rata 3.84 dan masuk ke dalam kriteria penilaian 3.40 - 4.19 yaitu tinggi. Karyawan PT. Aura Bali Craft yang menjadi responden dalam penelitian ini setuju bahwa efikasi diri kreatif merupakan nilai yang karyawan tersebut rasakan ketika bekerja. 
Tabel 8.

Deskripsi Jawaban Responden Mengenai Penilaian terhadap Variabel Kreativitas Karyawan

\begin{tabular}{|c|c|c|c|c|c|c|c|c|c|}
\hline \multirow{2}{*}{ No. } & \multirow{2}{*}{$\begin{array}{l}\text { Pernyataan Krativitas } \\
\text { Karyawan (Y1) }\end{array}$} & \multicolumn{5}{|c|}{ Jawaban Responden } & \multirow[t]{2}{*}{$\begin{array}{l}\text { Jml. } \\
\text { Res. }\end{array}$} & \multirow[t]{2}{*}{$\begin{array}{l}\text { Rata- } \\
\text { Rata }\end{array}$} & \multirow[t]{2}{*}{ Ket. } \\
\hline & & 1 & 2 & 3 & 4 & 5 & & & \\
\hline 1 & Orisinalitas & 0 & 0 & 10 & 43 & 9 & 33 & 3.97 & Tinggi \\
\hline 2 & $\begin{array}{l}\text { Keberanian mengambil risiko } \\
\text { terhadap ide baru }\end{array}$ & 0 & 2 & 5 & 15 & 11 & 33 & 4.06 & Tinggi \\
\hline 3 & $\begin{array}{l}\text { Menemukan fungsi baru dari } \\
\text { peralatan yang sudah ada }\end{array}$ & 0 & 4 & 8 & 13 & 8 & 33 & 3.76 & Tinggi \\
\hline 4 & Pemecahan masalah & 0 & 4 & 5 & 14 & 10 & 33 & 3.91 & Tinggi \\
\hline 5 & Selalu mencoba hal baru & 0 & 1 & 4 & 23 & 5 & 33 & 3.97 & Tinggi \\
\hline 6 & $\begin{array}{l}\text { Mengidentifikasi peluang } \\
\text { terhadap produk atau proses baru }\end{array}$ & 1 & 7 & 12 & 12 & 1 & 33 & 3.15 & Tinggi \\
\hline 7 & Menghasilkan ide unik & 2 & 4 & 7 & 12 & 8 & 33 & 3.61 & Tinggi \\
\hline & Rata $-\mathbf{r}$ & & & & & & & 3.78 & Tinggi \\
\hline
\end{tabular}

Sumber: Data Primer Diolah, 2018

Tabel 8 memaparkan penilaian responden terhadap 7 pernyataan mengenai kreativitas karyawan pada PT. Aura Bali Craft yang dijawab oleh 33 responden. Pernyataan kreativitas karyawan mendapatkan penilaian rata - rata 3.78 dan masuk dalam kriteria penilaian 3.40 - 4.19 yaitu tinggi. Ini berarti karyawan PT. Aura Bali Craft setuju bahwa kreativitas karyawan merupakan nilai yang dirasakan ketika bekerja.

Tabel 9 memaparkan mengenai angka dalam Kolmogorov-Smirnov sebesar 0,128 yang dimana skor pada Asymp. Sig. (2-tailed) sebesar 0,183. Angka yang didapat tersebut memaparkan dimana model dalam persamaan model regresi dalam kajian ini dikatakan bahwa berdistribusi normal dikarenakan nilai Asymp. Sig. (2-tailed) yang didapatkan lebih besar dari angka 0,05. 
Tabel 9.

Hasil Uji Normalitas Struktur 1

\begin{tabular}{lc}
\hline & Unstandardized Residual \\
\hline $\mathrm{N}$ & 33 \\
Kolmogorov-Smirnov & 0.128 \\
Asymp. Sig. (2-tailed) & 0.183 \\
\hline Sumber: Data Primer Diolah, 2018
\end{tabular}

Tabel 10.

Hasil Uji Normalitas Struktur 2

\begin{tabular}{lc}
\hline & Unstandardized Residual \\
\hline $\mathrm{N}$ & 33 \\
Kolmogorov-Smirnov & 0.121 \\
Asymp. Sig. (2-tailed) & 0.200 \\
\hline
\end{tabular}

Sumber: Data Primer Diolah, 2018

Tabel 10 memaparkan dimana angka dalam Kolmogorov-Smirnov sebesar 0,121 yang dimana skor pada Asymp. Sig. (2-tailed) sebesar 0,200. Angka yang didapat tersebut menjelaskan dalam persamaan model regresi yang dibuat tersebut dikatakan berdistribusi normal dikarenakan nilai Asymp. Sig. (2-tailed) yang lebih besar dari angka 0,05 .

Tabel 11.

Hasil Uji Multikolinearitas

\begin{tabular}{llcc}
\hline \multicolumn{1}{c}{ Persamaan Struktur } & \multicolumn{1}{c}{ Variabel } & Tolerance & VIF \\
\hline $\mathrm{M}_{1}=\beta_{2} \mathrm{X}_{1}+\mathrm{e}_{1}$ & $\begin{array}{l}\text { Kepemimpinan } \\
\text { Transformasional }\left(\mathrm{X}_{1}\right)\end{array}$ & 1.000 & 1.000 \\
$\mathrm{Y}_{1}=\beta_{3} \mathrm{M}_{1}+\beta_{1} \mathrm{X}_{1}+\mathrm{e}_{2}$ & $\begin{array}{l}\text { Kepemimpinan } \\
\text { Transformasional }\left(\mathrm{X}_{1}\right)\end{array}$ & 0.465 & 2.153 \\
& Efikasi Diri Kreatif $\left(\mathrm{M}_{1}\right)$ & 0.465 & 2.153
\end{tabular}

Sumber: Data Primer Diolah, 2018

Tabel 11 memaparakan angka tolerance serta VIF pada variabel kepemimpinan transformasional dan efikasi diri kreatif memperlihatkan angka tolerance dalam variabel yang dimana lebih besar dari angka 10 persen serta nilai 
Ida Ayu Dewi Wijayanti, Pengaruh Kepemimpinan Transformasional...

VIF yang didapat lebih kecil dari angka 10 dimana dalam persamaan model regresi dapat dinyatakan bebas dari aspek multikolinearitas.

Tabel 12.

Hasil Uji Heteroskedastisitas Struktur 1

\begin{tabular}{llccccc}
\hline \multirow{2}{*}{ Model } & \multicolumn{3}{c}{ Unstandardized Coefficient } & $\begin{array}{c}\text { Standardized } \\
\text { Coefficient }\end{array}$ & $\mathrm{t}$ & Sig. \\
\cline { 3 - 7 } & & $\mathrm{B}$ & Std. Error & Beta & \\
\hline 1 & (Constant) & 0.124 & 0.317 & & 0.391 & 0.699 \\
& Kepemimpinan & 0.054 & 0.077 & 0.124 & 0.694 & 0.493 \\
& Transformasional & & & & & \\
\hline
\end{tabular}

Sumber: Data Primer Diolah, 2018

Tabel 12 memaparkan nilai signifikansi daripada variabel kepemimpinan transformasional dengan nilai 0,699. Angka yang didapatkan lebih besar dari 0,05 ini berarti tidak ada pengaruh antar variabel bebas dengan absolute residual. Sehingga model yang ada dalam penelitian yang dibuat tidak mengalami gejala heteroskedastisitas.

Tabel 13.

Hasil Uji Heteroskedastisitas Struktur 2

\begin{tabular}{llccccc}
\hline \multirow{2}{*}{ Model } & \multicolumn{2}{c}{ Unstandardized Coefficient } & $\begin{array}{c}\text { Standardized } \\
\text { Coefficient }\end{array}$ & $\mathrm{t}$ & Sig. \\
\cline { 2 - 6 } & $\mathrm{B}$ & Std. Error & Beta & \\
\hline 2 & $\begin{array}{l}\text { (Constant) } \\
\text { Kepemimpinan }\end{array}$ & 0.391 & 0.261 & & 1.497 & 0.145 \\
$\begin{array}{l}\text { Transformasional } \\
\text { Efikasi Diri Kreatif }\end{array}$ & 0.106 & 0.093 & 0.287 & 1.141 & 0.263 \\
\hline
\end{tabular}

Sumber: Data Primer Diolah, 2018

Tabel 13 memaparkan nilai signifikansi variabel kepemimpinan transformasional mendapatkan skor sebesar 0,263 serta variabel dari efikasi diri kreatif sebesar 0,060. Angka tersebut melebihi 0,05 yang dimana berarti tidak ada pengaruh antar variabel bebas dengan absolute residual. Sehingga model dalam kajian ini tidak ada aspek dari gejala heteroskedastisitas. 
Hasil Tabel 14 dan 15 maka persamaan struktur sebagai berikut.

Persamaan Struktur 1

$$
\begin{aligned}
M_{1}=\beta_{2} X_{1} & +e_{1} \\
M_{1}=0,732 & X_{1}+e_{1} \\
\varepsilon_{1}\left(\text { error }_{1}\right) & =\sqrt{1-\mathrm{R}^{2}} \\
& =\sqrt{1-0,535} \\
& =0,681
\end{aligned}
$$

Tabel 14.

Hasil Analisis Jalur Struktur 1

\begin{tabular}{lcccc}
\hline \multicolumn{1}{c}{ Variabel } & $\begin{array}{c}\text { Standardized } \\
\text { Coefficient }\end{array}$ & Std. Error & thitung & Sig. uji t \\
\hline (Constant) & & 0.577 & 0.725 & 0.474 \\
Kepemimpinan & 0.732 & 0.141 & 5.978 & 0.000 \\
Transformasional (X) & & & & \\
R Squares & 0.535 & & & \\
F Statistik & 35.732 & & & \\
Sig. Uji F & 0.000 & & & \\
\hline
\end{tabular}

Sumber: Data Primer Diolah, 2018

Persamaan Struktur 2

$$
\begin{aligned}
Y_{1}=\beta_{3} M_{1} & +\beta_{1} X_{1}+e_{2} \ldots \ldots \ldots . . \\
Y_{1}=0,652 & M_{1}+0,286 X_{1}+e_{2} \\
e_{2}(\text { error } 2) & =\sqrt{1-R^{2}} \\
& =\sqrt{1-0,779} \\
& =0,470
\end{aligned}
$$

Hasil analisis yang didapat dari perhitungan e1 dan e2 dimana menghitung koefisien determinasi total yakni sebagai berikut.

$$
\begin{aligned}
\mathrm{R}^{2}{ }_{\mathrm{ms}}=1-\left(\mathrm{e}_{1}\right)^{2}\left(\mathrm{e}_{2}\right)^{2} & =1-(0,681)^{2}(0,470)^{2} \ldots \ldots \ldots \ldots \ldots \\
& =1-(0,463)(0,220)=0,898
\end{aligned}
$$


Tabel 15.

Hasil Analisis Jalur Struktur 2

\begin{tabular}{lcccc}
\hline \multicolumn{1}{c}{ Variabel } & $\begin{array}{c}\text { Standardized } \\
\text { Coefficient }\end{array}$ & Std. Error & t hitung & Sig. uji t \\
\hline (Constant) & 0.286 & 0.418 & -0.158 & 0.709 \\
Kepemimpinan & 0.652 & 0.148 & 2.270 & 0.031 \\
Transformasional (X) & 0.779 & & 5.176 & 0.000 \\
Efikasi Diri Kreatif (M) & 52.887 & & & \\
R Squares & 0.000 & & & \\
F Statistik & & & & \\
Sig. Uji F & & & & \\
\hline
\end{tabular}

Sumber: Data Primer Diolah, 2018

Nilai determinasi total yang di dapat sebesar 0,898 dimana nilai tersebut mempunyai makna bahwa sebesar 89,8 persen variasi kreativitas karyawan dipengaruhi dengan variasi kepemimpinan transformasional dan efikasi diri kreatif, sementara lainnya dengan nilai 10,2 persen dapat dijelaskan dengan faktor-faktor lain yang belum digunakan ke dalam model kajian.

Pengujian pada variabel mediasi dimana memediasi hubungan antar variabel terikat dengan variabel bebas menggunakan uji sobel dari pengaruh kepemimpinan transformasional terhadap kreativitas karyawan melalui efikasi diri kreatif dapat dilakukan melalui tahapan sebagai berikut.

Menghitung nilai

$$
\begin{aligned}
& \mathrm{Sab}=\sqrt{\mathrm{b}^{2} \mathrm{Sa}^{2}+\mathrm{a}^{2} \mathrm{Sb}^{2}} \ldots \ldots \ldots \ldots \ldots \ldots \ldots \\
& \mathrm{Sab}=\sqrt{0,668^{2} 0,141^{2}+0,841^{2} 0,129^{2}} \\
& \mathrm{Sab}=0,16
\end{aligned}
$$

Menghitung nilai ab

$\mathrm{ab}=0,841 \times 0,668$

$\mathrm{ab}=0,561$ 
Menghitung nilai Z

$$
\begin{aligned}
& \mathrm{Z}=\frac{a}{s} \\
& \mathrm{Z}=3,50
\end{aligned}
$$

Hasil perhitungan daripada Tabel 15 ditunjukan tingkat signifikansi kepemimpinan transformasional sebesar $0,000<0,05$ dimana nilai beta 0,286 oleh karena itu hipotesis penelitian $\mathrm{H}_{1}$ diterima ini berarti kepemimpinan transformasional berpengaruh positif dan signifikan terhadap kreativitas karyawan pada PT. Aura Bali Craft. Hasil perhitungan pada Tabel 14 yang dimana dipaparkan nilai tingkat signifikansi kepemimpinan transformasional sebesar $0,000<0,05$ dan diperoleh nilai beta sebesar 0,732 oleh karena itu hipotesis penelitian $\mathrm{H}_{2}$ diterima ini berarti kepemimpinan transformasional berpengaruh positif dan signifikan terhadap efikasi diri kreatif pada PT. Aura Bali Craft. Hasil perhitungan pada Tabel 7 menjelaskan bahwa nilai tingkat signifikansi dari efikasi diri kreatif sebesar 0,000 $<0,05$ dengan angka beta 0,652 dimana hipotesis dalam penelitian $\mathrm{H}_{3}$ diterima ini dimaknakan dengan efikasi diri kreatif berpengaruh positif dan signifikan terhadap kreativitas karyawan pada PT. Aura Bali Craft. Hasil perhitungannya sehingga didapatkan perbandingan dimana nilai $\mathrm{Z}$ hitung sebesar 3,50> Z tabel sebesar 1,96 maka dapat dibuat hipotesis penelitian $\mathrm{H}_{4}$ diterima yang dimaksudkan ialah efikasi diri kreatif mampu memediasi secara signifikan pengaruh kepemimpinan transformasional terhadap kreativitas karyawan. 
Ida Ayu Dewi Wijayanti, Pengaruh Kepemimpinan Transformasional...

\section{SIMPULAN}

Simpulan penelitian ini apabila dilihat berdasarkan hasil analisis penelitian dan hasil pembahasan yaitu pertama, kepemimpinan transformasional berpengaruh positif dan signifikan terhadap kreativitas karyawan pada PT. Aura Bali Craft. Hal ini menunjukkan bahwa semakin baik gaya kepemimpinan transformasional diterapkan makan kreativitas karyawan PT. Aura Bali Craft akan semakin tinggi. Kedua, kepemimpinan transformasional berpengaruh positif dan signifikan terhadap efikasi diri kreatif pada PT. Aura Bali Craft. Ini dimaksudkan apabila semakin bagus gaya kepemimpinan transformasional yang diterapkan makan efikasi diri kreatif karyawan PT. Aura Bali Craft akan semakin tinggi. Ketiga, efikasi diri kreatif berpengaruh positif dan signifikan terhadap kreativitas karyawan pada PT. Aura Bali Craft. Hal ini menunjukkan apabila karyawan tersebut yakin akan kemampuan kreatif yang dimilikinya maka kreativitas karyawan menjadi semakin tinggi. Keempat, efikasi diri kreatif secara signifikan memediasi pengaruh kepemimpinan transformasional terhadap kreativitas karyawan. Hal yang didapat menunjukkan bahwa kepemimpinan transformasional yang diterapkan dengan baik akan meningkatkan efikasi diri kreatif karyawan, apabila efikasi diri kreatif tersebut meningkat maka secara tidak langsung akan meningkatkan kreativitas karyawan PT. Aura Bali Craft.

Saran pada penelitian ini berdasarkan hasil analisis penelitian dan kesimpulan adalah pertama, upaya untuk meningkatkan gaya kepemimpinan transformasional yang diterapkan oleh PT. Aura Bali Craft menjadi lebih baik, 
maka pemimpin harus mampu untuk mengabaikan kepentingan pribadi demi kepentingan perusahaan untuk meningkatkan kemampuannya menjadi lebih baik lagi sehingga karyawan merasa betah dan nyaman ketika bekerja. Kedua, upaya untuk meningkatkan efikasi diri kreatif karyawan PT. Aura Bali Craft menjadi lebih baik, karyawan harus mampu untuk menyelesaikan masalah yang rumit secara efisien, sehingga karyawan dapat bertindak secara kreatif. Ketiga, upaya untuk meningkatkan kreativitas karyawan PT. Aura Bali Craft menjadi lebih baik, maka karyawan harus mampu mengidentifikasi peluang-peluang yang ada terhadap suatu produk sehingga karyawan yakin akan kemampuannya untuk menghasilkan kreativitas yang tinggi.

\section{REFERENSI}

Afsar, Bilal dan Mariam Massod. (2017). Transformasional Leadership, Creative Self-Efficacy, Trust in Supervisor, Uncertainty Avoidance, and Innovative Work Behavior of Nurses. The Journal of Applied Behavioral Science. 00 (0). Hal. 1-26.

Bakhtiar, Arfan, Sriyanto dan Amalia. (2009). Analisis Faktor-faktor yang Mempengaruhi Perkembangan Kreativitas pada Industri Kerajinan Batik. J@TI Undip. IV (1). Hal. 23-34.

Bandura, Albert. (2007). Much Do Over Faculty Conception on Perceive Selfefficacy Ground in Faculty Experiment. Journal of Social and Clinical Psychology. 26 (6). Hal 641-658.

Bass, Bernard M. dan Bruce J. Avolio. (1992). Develop Transformational Leadership: 1992 'nd Beyond. Journal of European Industrial Training. 14 (5). Hal 21-27.

Chen, Yanhong dan Li Zhang. (2017). Be Creative Pro-active? The Impacts by Creative Self-efficacy on Employees Creativity: Pro-active Perspective. Springer Science: Business Media. 
Cheung, Millissa F.Y. dan Chi-Sum Wong. (2011). Transformational Leadership, Leaders Support, and Employees Creativity. Leadership and Organization Development Journal. 32 (7). Hal. 656-672.

Gibson, James L., John. M. Ivancevich dan James H. Donnelly, JR. Organisasi Edisi Kedelapan. Binarupa Aksara: Jakarta

Gong, Yaping, Chi Huang dan Jiing-Lih Farh. (2009). Employee Learnin' Orientation, Transformational Leadership, and Employee Creativity: The Mediating Role of Employee Efikasi diri kreatif. Academy of Management Journal. 52 (4). Hal. 765-778.

Gumusluoglu Lale dan Arzu Ilsev. (2009). Transformational Leadership, Creativity and Organizational Innovation. Journal of Business Research. 62. Hal 461-473.

Henker Nils, Sabine Sonentag dan Dana Unger. (2014). Transformational Leadership, Employees Creativity: The Mediatian Roles by Promotion Focus and Creative Process Engagement. Springer Science Business Media: New York.

Hirst, Giles, Dan vann Knipenberg, Qin Zhou, Cherrie Jiuhua Zhu dan Philip Cheng-Fei Tsai. (2015). Exploitation and Exploration Climates' Influence on Performance and Creativity: Diminishing Returns as Function of SelfEfficacy. Journal of Management. XX (X). Hal. 1-22.

Karwowski, Maciej. (2011). It Does not to Ask, But Sometime Its Hurt to Believe: Polis Student Creative Self-efficacy and It is Predictors. Psychology of Aesthetic, Creativity, and The Arts. 5 (2). Hal. 154-164.

Malik, Muhammad Abdur Rahman, Arif N. But dan Jin Nam Choi. (2015). Rewards and Employee Creative Performance: Moderating Effects of Efikasi diri kreatif, Reward Importance, and Locus of Control. Journal of Organizational Behavior. 36. Hal. 59-74.

Marasabessy, Zainal Abidin dan Budi Santoso. (2014). Pengaruh Dorongan melalui Rekan Kerja pada Kreativitas Karyawan dengan Autonomi Kerja dan Efikasi-diri Kreatif sebagai Pemoderasi. Jurnal Siasat Bisnis. 18 (1). Hal. 32-44.

Mittal, Swati dan Rajib Lochan Dhar. (2015). Transformational Leadership and Employees Creativity as a Mediator Roles of Efikasi diri kreatif and Moderating Roles of Knowledge Sharing. Management Decisions. 53 (5). Hal. 894-910. 
Mustika, Mona Satria. (2017). Pengaruh Kepribadian Pro-aktif Pada Kreativitas Karyawan dengan Kepemimpinan Transformasional serta Autonomi Kerja Sebagai Variabel Moderasi. Jurnal Bisnis Darmajaya. 3 (2). Hal. 126-145.

Newman, Alexander, Herman Tse, Gary Schwarz dan Ingrid Nielsen. (2018). The Effect of Employee Creatives Self-Efficacy on Innovative Behavior: The Role of Entreprenurial Leadership. Journal of Business Research. 89. Hal. $1-9$.

Rizi, Rezvan Mirsafaei, Aida Azadi, Maryam Eslami Farsani dan Shahram Aroufzad. Relationship Between Leadership Styles and Job Satisfaction Among Physical Education Organizations Employees. European Journal of Sports and Exercise Science. 2 (1). Hal. 7-11.

Robbins, Stephen P., Timothy A. Judge. (2015). Perilaku Organisasi. Salemba Empat: Jakarta.

Sanny, Lim, Raden Ajeng Bebby Cahyani dan Yogi Andhika. 2013. Analisis Pengaruh Lingkungang Kerja dan Motivasi terhadap Kreativitas Karyawan Perum Pegadaian (Kantor Wilayah). Binus Business Review. 4 (1). Hal. 389397.

Shin, Shung J., Tae-Yoel Kim, Jeong-Yoen Lee dan Lin Bian. Cognitive Team Diversity and Individual Team Members Creativity: A Crosslevel Interactions. Academy of Management Journal. 55 (1). Hal. 197-212.

Sugiyono. (2014). Metode Penelitian Pendidikan Pendekatan Kuatitatif, Kualitatif dan $R \& D$. Bandung: Alfabeta.

Song, Jung, Changqing He, Wei Wu dan Xuesong Zhai. (2018). Role of SelfEfficacy and Transformastional Leadership in Explain Voice-Job Satisfaction Realtionship. Current Psychology - Springer Science Business Media.

Tierney, Pamela dan Steven M. Farmer. (2011). Efikasi diri kreatif Development and Creative Performance Over. Journal of Applied Psychology. 96 (2). Hal. 277-293.

Wang, Chung, Huei Tsai, Tien Tsai. (2014). Linkin Transformational Leadership and Employee Creativity in The Hospitality Industry: The Influences of Creative Role Identity, Efikasi diri kreatif, and Job Complexity. Tourism Management. 40. Hal. 79-89.

Waterwall, Brian, Bryan Fuller, Heather Budden. (2017). Understand The Inner Dwell: Intergrating The Efikasi diri kreatif Literature. Journal of Managerial Issues. 29 (2). Hal. 189-210. 
Ida Ayu Dewi Wijayanti, Pengaruh Kepemimpinan Transformasional...

Wirawan, N. (2014). Cara Mudah Memahami Statistika Ekonomi dan Bisnis (Statistika Inferensi) Edisi ketiga. Keraras Emas. Bali. 